\section{AINA NEWS}

\section{Prestigious Award for AINA Fellow}

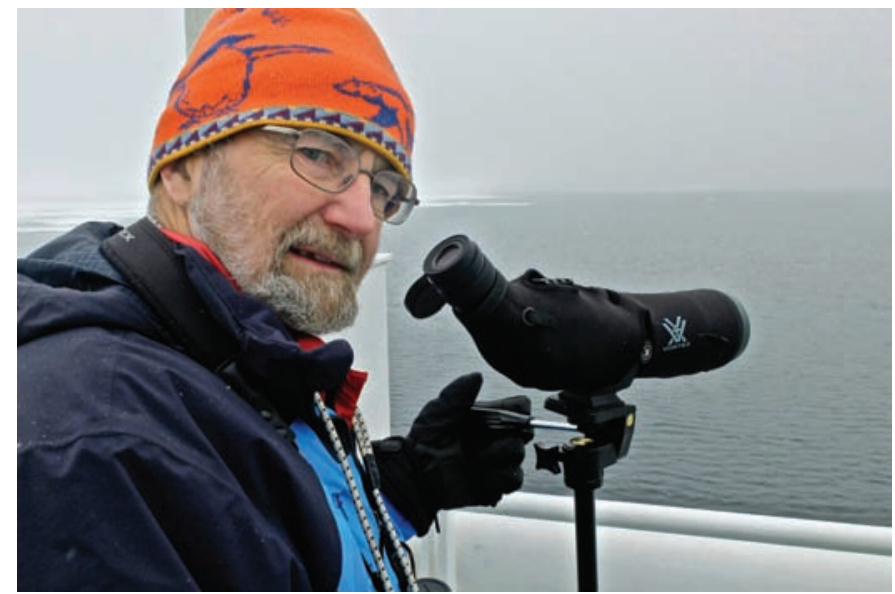

Dr. lan Stirling scanning for polar bears in Svalbard. (Photo: Mette Eliseussen.)

This past December, long-time AINA Fellow Dr. Ian Stirling was awarded the Weston Family Prize for Lifetime Achievement in Northern Research for 2015. Dr. Stirling is a renowned polar marine mammal scientist, who has conducted groundbreaking research on the ecology of polar bears and ice-breeding seals for almost five decades. Dr. Stirling was a research scientist with Environment Canada until 2007 and is currently an emeritus research scientist there, as well as an adjunct professor in the Department of Biological Sciences at the University of Alberta. He served the Arctic Institute for many years as an advisor on Arctic's Editorial Board and has published more than 20 research papers in Arctic, beginning in 1980. The Weston Family Prize was presented to Dr. Stirling at ArcticNet's 2015 Annual Scientific Meeting in Vancouver, British Columbia, in December.

The \$50,000 Weston Family Prize, which is awarded annually to a leading northern researcher in the natural sciences, is administered by the Association of Canadian Universities for Northern Studies and funded by the W. Garfield Weston Foundation. Past recipients of the prize are Dr. Charles Krebs (2014), Dr. John Smol (2013), Dr. Louis Fortier (2012), and Dr. Serge Payette (2011).

\section{Data and Information Services Welcomes New Team Members}

Data and Information Services is pleased to announce that Vinay Rajdev has joined our team as an Information Analyst for the Arctic Science and Technology Information System (ASTIS). Vinay has previously worked as a researcher for the Arctic Institute and for the Health, Environment and Indigenous Research Group at Trent University. Vinay's Arctic background includes working with Inuit communities on food security in Arctic Canada, risk

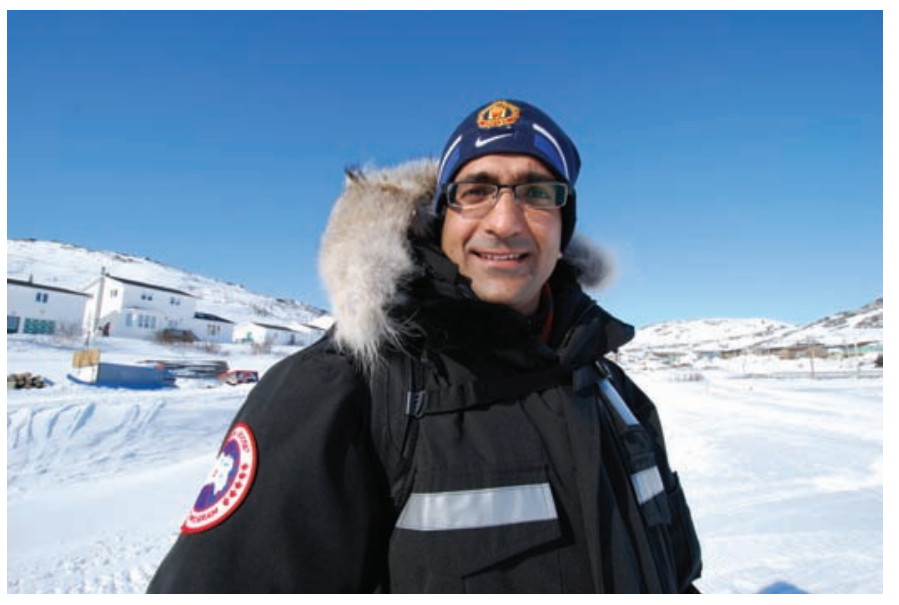

Vinay Rajdev in Hopedale, Nunatsiavut, while conducting fieldwork on Inuit food security in March 2012. (Photo: Kristeen McTavish.)

communication on contaminants, social and economic issues affecting communities, climate change and health impact, and water issues. He has also worked on Inuit knowledge and land use studies. Vinay has experience with Arctic geography, indexing and data entry, and website development. He holds a BSc in Environmental Science from Trent University and a Master of Resource and Environmental Management from Dalhousie University. We are very happy to welcome him to ASTIS!

Data and Information Services is also happy to welcome practicum student Andrea Bailey. Andrea is currently

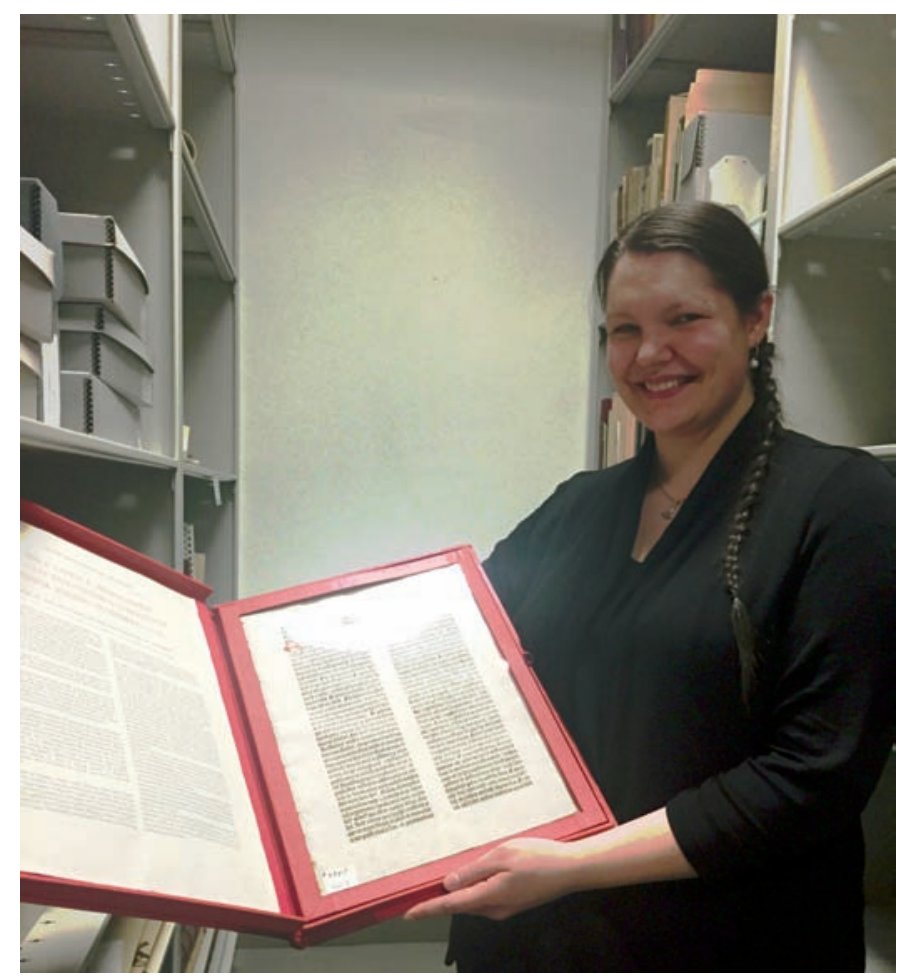

Andrea Bailey visiting the Arctic Institute's Special Collections (Photo: Shannon Vossepoel.) 
completing her practicum for the University of Calgary's Museum and Heritage Studies program with the Arctic Institute. Andrea has been working on the Institute's collaboration with the Military Museums on The Cold Before the War: Operation Muskox and Beyond exhibit. She has also been organizing and creating an inventory of the Institute's art and artifacts collections. Andrea is scheduled to graduate with her Bachelor of Arts in Greek and Roman Studies in June 2016.

The Cold Before the War: Operation Muskox and Beyond

The Arctic Institute of North America, in partnership with Libraries and Cultural Resources at the University of Calgary, is pleased to present The Cold Before the War: Operation Muskox and Beyond, at the Founders' Gallery of The Military Museums in Calgary, Alberta, Canada.

The exhibit charts military action in the Arctic from 1946 and showcases the Arctic Institute's extensive photo archive as well as select artifacts. The exhibit is a companion to Mapping a Cold War, an exhibition by contemporary artist Leslie Reid that highlights the role the North plays within Canada and the entwined nature of defence and environment. Mapping a Cold War exhibits concurrently with The Cold Before the War in the Founders' Gallery.

The exhibit opened on 26 February 2016, and will run through 5 June 2016.

\section{ArcticConnect Update}

ArcticConnect's Arctic Sensor Web (ASW) was recently upgraded with a new search interface. Arctic Sensor Web enables research stations around the pan-Arctic to connect their sensors to a cloud service for visualization, information, and collaborative analysis. Arctic Sensor Web currently contains sensor information for more than 550 research stations in the circumpolar Arctic. Access it online at http://sensorthings.arcticconnect.org. 